\title{
Posttraumatic stress and myocardial infarction risk perceptions in hospitalized acute coronary syndrome patients
}

\section{Donald Edmondson*, Jonathan A. Shaffer, Ellen-Ge Denton, Daichi Shimbo and Lynn Clemow}

Center for Behavioral Cardiovascular Health, Columbia University Medical Center, New York, NY, USA

\section{Edited by:}

Gian Mauro Manzoni, Istituto Auxologico Italiano IRCCS, Italy

Reviewed by:

Luca Filipponi, Unversità di Padova, Italy

Paraskevi Theofilou, Panteion University of Social and Political Sciences, Greece

${ }^{*}$ Correspondence:

Donald Edmondson, Center for Behavioral Cardiovascular Health, Columbia University Medical Center, 622 West 168 Street, PH9-948,

New York, NY 10032, USA.

e-mail:dee2109@columbia.edu
Posttraumatic stress disorder (PTSD) is related to acute coronary syndrome (ACS; i.e., myocardial infarction or unstable angina) recurrence and poor post-ACS adherence to medical advice. Since risk perceptions are a primary motivator of adherence behaviors, we assessed the relationship of probable PTSD to ACS risk perceptions in hospitalized ACS patients $(n=420)$. Participants completed a brief PTSD screen 3-7 days post-ACS, and rated their 1-year ACS recurrence risk relative to other men or women their age. Most participants exhibited optimistic bias (mean recurrence risk estimate between "average" and "below average"). Further, participants who screened positive for current PTSD $(n=15)$ showed significantly greater optimistic bias than those who screened negative $(p<0.05)$, after adjustment for demographics, ACS severity, medical comorbidities, depression, and self-confidence in their ability to control their heart disease. Clinicians should be aware that psychosocial factors, and PTSD in particular, may be associated with poor adherence to medical advice due to exaggerated optimistic bias in recurrence risk perceptions.

Keywords: PTSD, cardiovascular disease, acute coronary syndrome, myocardial infarction, risk perceptions, secondary prevention

\section{INTRODUCTION}

Acute coronary syndromes [ACS; i.e., myocardial infarction (MI), unstable angina (UA)] are highly prevalent (Lloyd-Jones et al., 2010), and survivors are at increased risk for recurrent MI and mortality in the subsequent year (Goldberg et al., 2004; Montalescot et al., 2007). Although this increased risk can be managed through adherence to medical advice, post-ACS patients often exhibit poor adherence (Eagle et al., 2005), possibly due to underestimation of their risk for future MI recurrence. This may be particularly true for patients with posttraumatic stress disorder (PTSD), an anxiety disorder that has been related to ACS incidence (Kubzansky et al., 2007), ACS recurrence (Edmondson et al., 2011), poor post-ACS adherence (Shemesh et al., 2004), and ACS risk behaviors (Cohen et al., 2009).

It is widely known that affective states, and more abiding affective alterations due to psychological disorder, are related to risk perceptions. However, the complexity of the relationship between affect and risk perception is under-recognized, as the effect of emotions are influenced by the type and intensity of emotion, as well as the type of judgment being influenced (Pham, 2007). For example, depression disrupts reasoning and effortful processing (Conway and Giannopoulos, 1993; Hartlage et al., 1993), and clinical anxiety is related poorer recall for pertinent information and organization of such information in memory (Mueller, 1978), haphazard decision-making (Keinan, 1987), and less thorough processing of persuasive arguments (Sanbonmatsu and Kardes, 1988). Thus, psychological disorders may produce deficits in people's reasoning abilities.
The estimation of risk for many future events is a difficult task under any circumstances, and the estimation of a future life-threatening event such as an MI immediately after experiencing an MI may be particularly difficult. It requires both some understanding of the base rate of MI, the added risk conferred by having already had an MI, and (in this study) a comparison of personal risk to normative risk. While the cognitive load associated with PTSD and the biases associated with anxiety more generally may influence risk perceptions, there is also evidence that when risk perceptions are related to actual subsequent outcomes, psychological disorder may be related to poor prediction and overconfidence due to neglect of base rate information, heightened perception of dissimilarity from others, and even undue optimism about the future (Dunning and Story, 1991).

The association of PTSD to medical risk perceptions has never been estimated, particularly in the context of actual elevated risk due to PTSD. Since risk perceptions are a primary motivator of adherence behaviors (Brewer et al., 2004), we assessed the relationship of probable PTSD to MI risk perceptions in hospitalized ACS patients.

\section{MATERIALS AND METHODS}

Participants were ACS patients who had been treated in the Columbia University Medical Center (CUMC) ED and enrolled in the Prescription Use, Lifestyle, Stress Evaluation (PULSE) study, an ongoing, single site, observational, prospective study of patients with ACS. The primary objectives of the parent study are to identify intermediary phenotypes of depression in ACS patients and the 
behavioral, biological, and genetic mechanisms that may account for the excess ACS recurrence and mortality risk associated with depression in ACS patients. Patients were eligible to participate if they were diagnosed with ACS, as defined by UA, NSTEMI, or STEMI, and diagnosis was confirmed by two independent cardiologists. Patients were ineligible if they were under 18 years old, a prisoner, were deemed unable to comply with the study protocol or had a life expectancy less than 1 year, were not fluent in English or Spanish, or evinced psychosis, bipolar disorder, or personality disorder.

Data for the present analyses are from a subset of the first 500 participants who also completed a PTSD screening measure in the 3 - to 7 -days post-ACS $(n=420)$.

During hospitalization, participants rated their "risk for having a heart attack in the next year compared to other men (or women) their age" on a 5-point scale (1, "much lower than average" to 5, "much higher than average"), and their confidence that they "could control their heart disease" on a 5point scale (1, "not at all confident" to 5, "very confident"). Patient-reported demographics and depressive symptoms (i.e., Beck Depression Inventory, BDI sum score; Beck et al., 1961) were also ascertained. The following clinical variables were derived from chart review: index ACS type (i.e., MI or UA), Global Registry of Acute Coronary Events (GRACE) risk score (i.e., 6-month post-ACS mortality risk based upon previous MI, heart failure, and in-hospital cardiovascular markers; Goldberg et al., 2004), and Charlson comorbidity score (i.e., index of 22 medical conditions weighted by mortality risk; Charlson et al., 1994). Demographics, depressive symptoms, and perceived control have been associated with risk perceptions in previous research (Avis et al., 1989; Helweg-Larsen and Shepperd, 2001).

Participants were screened 3-7 days after discharge from the hospital for PTSD symptoms in the previous three months using three items from the Structured Clinical Interview for DSM-IVPTSD (SCID-PTSD; First et al., 1995). They reported whether they had (1) experienced a traumatic event ("such as a major disaster, very serious accident or fire, being physically assaulted or raped, seeing another person killed or dead, or badly hurt, or hearing about something horrible that has just happened to someone close to you") prior to their ACS hospitalization, (2) whether the event came back "in nightmares, flashbacks, or thoughts you cannot get rid of," and (3) whether the experience of "thoughts or feelings coming back" had happened in the past 3 months. Participants who responded "yes" to all three items were categorized as screening positive for probable PTSD. In previous research, responses to these questions correctly identified 97\% of PTSD cases (Franklin et al., 2002). Finally, five cardiologists blinded to PTSD status estimated the aggregate 1-year MI risk for all participants based on demographic data and clinical risk index scores.

Myocardial infarction risk perceptions were the dependent variable in a one-way ANCOVA with probable PTSD screen as the grouping factor, and age, gender, race (African-American versus other), ethnicity (Hispanic versus non-Hispanic), index ACS event type, GRACE, Charlson, BDI, and self-confidence in heart disease control as covariates.

\section{RESULTS}

Participants were primarily male $(n=291,69 \%)$ and Hispanic $(n=287,68 \%)$ or African-American $(n=83,20 \%)$ with a mean age of $63 \pm 11$. For clinical variables, 161 participants (38\%) were hospitalized with MI, and the sample as a whole averaged 2 medical comorbidities. The average GRACE score for the sample was 88.8 (28.22), indicating $\sim 3-8 \%$ average probability of death between hospitalization and 6 months post-discharge. The sample as a whole reported moderate confidence in their ability to control their heart disease $[$ mean $=2.4(1.2)]$. Participants who screened positive for PTSD $(n=15,3.5 \%)$ did not differ from those who screened negative on any covariate (Table 1), except that they reported significantly more depressive symptoms (13.3 versus 9.2, $p=0.03)$.

Overall, participants exhibited an optimistic bias in perceived MI risk, rating their risk as between average and below average $[$ mean risk estimate $=2.6(1.1)]$. Patients' risk perceptions (Figure 1) were unrelated to their GRACE risk score $(r=0.05$, $p=0.31$ ), though qualitatively discrepant from cardiologists' ratings [between "above average" (four cardiologists) and "well above average" (one cardiologist) $]$. In the ANCOVA $[F(9,406)=9.36$, $\left.p<0.001, R^{2}(\operatorname{adj})=0.15\right]$, a positive screen for PTSD was associated with significantly lower perceived risk of MI relative to a negative screen [2.1 (1.0) versus $2.7(1.1) ; p=0.03, \eta^{2}=0.01$ ]. Significant covariates included confidence in ability to control heart disease $\left(p<0.001, \eta^{2}=0.09\right)$, Charlson comorbidity score $\left(p=0.01, \eta^{2}=0.02\right)$, and Hispanic ethnicity $\left(p=0.02, \eta^{2}=0.01\right)$.

\section{DISCUSSION}

This study is the first to assess MI risk perceptions in post-ACS patients and to demonstrate a relationship between PTSD and increased optimistic bias. Previous research suggested that PTSD might be related to less optimistic bias (Gidycz et al., 2006), but this previous research was not conducted among hospitalized patients. In contrast to laboratory experiments, psychological disorders have been associated with more pronounced optimistic bias in estimations of future events (Dunning and Story, 1991). Further, it is possible that the hospital environment induces avoidance and numbing mechanisms that further minimize risk perceptions in patients with probable PTSD. It is also possible that a broader

Table 1 | Participant characteristics.

\begin{tabular}{lll}
\hline & $\begin{array}{l}\text { Positive screen for } \\
\text { PTSD, } \boldsymbol{n}=\mathbf{1 5}\end{array}$ & $\begin{array}{l}\text { Negative screen for } \\
\text { PTSD, } \boldsymbol{n}=\mathbf{4 0 5}\end{array}$ \\
\hline Age, years & $61.2 \pm 12.3$ & $62.8 \pm 11.0$ \\
Male, $n(\%)$ & $11(73)$ & $280(69)$ \\
Hispanic/Latino, $n(\%)$ & $8(53)$ & $279(69)$ \\
African-American, $n(\%)$ & $3(20)$ & $80(20)$ \\
Myocardial infarction, $n(\%)$ & $7(47)$ & $154(38)$ \\
GRACE risk score & $80.8 \pm 23.9$ & $89.1 \pm 27.7$ \\
Charlson comorbidity index & $1.9 \pm 1.7$ & $1.7 \pm 1.7$ \\
Beck Depression Inventory* & $13.3 \pm 9.9$ & $9.2 \pm 7.2$ \\
Confidence in CHD control & $2.5 \pm 1.4$ & $2.3 \pm 1.1$ \\
\hline
\end{tabular}

${ }^{*} p<0.05$. 


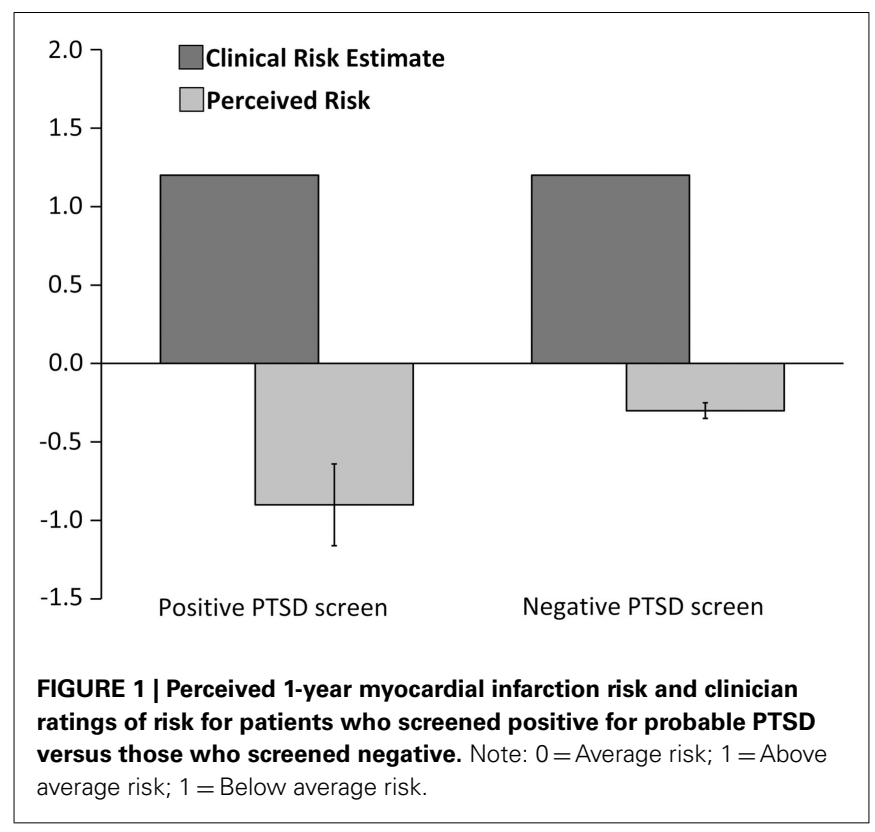

deficit in self-care gives rise to cognitive dissonance that requires a reduction in perceptions of future MI threat (Stone and Cooper, 2001). The self-care deficit and cognitive dissonance explanation is consistent with recent findings that PTSD is associated with longer delays between initial symptoms and presentation to the hospital in ACS patients (Newman et al., 2011).

There were no significant differences between the two groups on any demographic or clinical variable we measured, nor did the two groups differ in their confidence that they could control their heart disease. However, as expected, participants who screened positive for probable PTSD reported more depression

\section{REFERENCES}

Avis, N. E., Smith, K. W., and McKinlay, J. B. (1989). Accuracy of perceptions of heart attack risk: what influences perceptions and can they be changed? Am. J. Public Health 79, 1608-1612.

Beck, A. T., Ward, C. H., Mendelson, M., Mock, J., and Erbaugh, J. (1961). An inventory for measuring depression. Arch. Gen. Psychiatry 4, 561-571.

Brewer, N. T., Weinstein, N. D., Cuite, C. L., and Herrington, J. E. (2004). Risk perceptions and their relation to risk behavior. Ann. Behav. Med. 27, 125-130.

Carson, R. C., Hollon, S. D., and Shelton, R. C. (2010). Depressive realism and clinical depression. Behav. Res. Ther. 48, 257-265.

Charlson, M., Szatrowski, T. P., Peterson, J., and Gold, J. (1994). Validation of a combined comorbidity index. $J$. Clin. Epidemiol. 47, 1245-1251.

Cohen, B. E., Marmar, C., Ren, L., Bertenthal, D., and Seal, K. H. (2009). Association of

symptoms. While depression is often thought to result in "depressive realism," there is considerable disagreement concerning the consistency, strength, and source of this effect, particularly outside the lab (Carson et al., 2010). Indeed, we found the opposite, that the more depressed group were less realistic about their risk for MI, in a manner similar to that found by Dunning and Story (1991).

Limitations of this study include the use of a PTSD screening instrument which assesses only Criterion A (without specifying the type of trauma) and Criterion B. Although the low prevalence of probable PTSD in this sample is noteworthy and has important clinical implications, it is not a statistical limitation as unbalanced designs in ANCOVA tend to result in reduced power (i.e., bias the grand mean toward the larger sample). Further, we reported statistical tests based on Type III sums of squares in ANCOVA because estimates based on Type III sums of squares are not sample size dependent (i.e., effect estimates are not a function of group size). Future studies should consider more comprehensive measures of PTSD.

These results suggest that ACS patients with PTSD may be excessively optimistic when estimating their true risk of cardiovascular morbidity. This optimistic bias may help to explain the decreased adherence previously described in post-ACS patients with PTSD (Shemesh et al., 2004) and, ultimately, the increased ACS recurrence risk associated with PTSD (Edmondson et al., 2011; von Känel et al., 2011).

\section{ACKNOWLEDGMENTS}

This work was supported by Grants HL-088117 and CA-156709 from the National Institutes of Health, Bethesda, Maryland. Its contents are solely the responsibility of the authors and do not necessarily represent the official view of NCRR or NIH. Dr. Edmondson is supported by grant KM1CA156709.

Guideline-based standardized care is associated with substantially lower mortality in Medicare patients with acute myocardial infarction: the American College of Cardiology's Guidelines Applied in Practice (GAP) projects in Michigan. J. Am. Coll. Cardiol. 46, 1242-1248.

Edmondson, D., Rieckmann, N., Shaffer, J. A., Schwartz, J. E., Burg, M. M., Davidson, K. W., Clemow, L., Shimbo, D., and Kronish, I. (2011). Posttraumatic stress due to an acute coronary syndrome increases risk of 42-month major adverse cardiac events and all-cause mortality. $J$. Psychiatr. Res. 45, 1621-1626.

First, M., Spitzer, R. L., Gibbon, M., and Williams, J. B. W. (1995). Structured Clinical Interview for Axis I DSM-IV Disorders. New York: New York State Psychiatric Institute.

Franklin, C. L., Sheeran, T., and Zimmerman, M. (2002). Screening for trauma histories, posttraumatic stress disorder (PTSD), and subthreshold PTSD in psychiatric outpatients. Psychol. Assess. 14, 467-471.

Gidycz, C. A., McNamara, J. R., and Edwards, K. M. (2006). Women's risk perception and sexual victimization: a review of the literature. Aggress. Violent Behav. 11, 441-456.

Goldberg, R. J., Currie, K., White, K., Brieger, D., Steg, P. G., Goodman, S. G., Dabbous, O., Fox, K. A., and Gore, J. M. (2004). Six-month outcomes in a multinational registry of patients hospitalized with an acute coronary syndrome (The Global Registry of Acute Coronary Events [GRACE]). Am. J. Cardiol. 93 , 288-293.

Hartlage, S., Alloy, L. B., Vázquez, C., and Dykman, B. (1993). Automatic and effortful processing in depression. Psychol. Bull. 113, 247-278.

Helweg-Larsen, M., and Shepperd, J. A. (2001). Do moderators of the optimistic bias affect personal or target risk estimates? A review of the literature. Pers. Soc. Psychol. Rev. 5, 74-95. 
Keinan, G. (1987). Decision making under stress: scanning of alternatives under controllable and uncontrollable threats. J. Pers. Soc. Psychol. 52, 639-644.

Kubzansky, L. D., Koenen, K. C., Spiro, A., Vokonas, P. S., and Sparrow, D. (2007). Prospective study of posttraumatic stress disorder symptoms and coronary heart disease in the Normative Aging Study. Arch. Gen. Psychiatry 64, 109-116.

Lloyd-Jones, D., Adams, R. J., Brown, T. M., Carnethon, M., Dai, S., De Simone, G., Ferguson, T. B., Ford, E., Furie, K., Gillespie, C., Go, A., Greenlund, K., Haase, N., Hailpern, S., Ho, P. M., Howard, V., Kissela, B., Kittner, S., Lackland, D., Lisabeth, L., Marelli, A., McDermott, M. M., Meigs, J., Mozaffarian, D., Mussolino, M., Nichol, G., Roger, V. L., Rosamond, W., Sacco, R., Sorlie, P., Roger, V. L., Thom, T., Wasserthiel-Smoller, S., Wong, N. D., Wylie-Rosett, J., and American Heart Association Statistics Committee and Stroke Statistics Subcommittee. (2010). Heart disease and stroke statistics - 2010 update: a report from the American Heart Association. Circulation 121, 948-954.

Montalescot, G., Dallongeville, J., Van Belle, E., Rouanet, S., Baulac, C., Degrandsart, A., and Vicaut, E. (2007). STEMI and NSTEMI: are they so different? 1-year outcomes in acute myocardial infarction as defined by the ESC/ACC definition (the OPERA registry). Eur. Heart J. 28, 1409-1417.

Mueller, J. H. (1978). The effects of individual differences in test anxiety and type of orienting task on levels of organization in free recall. J. Res. Pers. 12, 100-116.

Newman, J. D., Muntner, P., Shimbo, D., Davidson, K. W., Shaffer, J. A., and Edmondson, D. (2011). Posttraumatic stress disorder (PTSD) symptoms predict delay to hospital in patients with acute coronary syndrome. PLoS ONE 6, e27640. doi:10.1371/journal.pone.0027640

Pham, M. T. (2007). Emotion and rationality: a critical review and interpretation of empirical evidence. Rev. Gen. Psychol. 11, 155.

Sanbonmatsu, D. M., and Kardes, F. R. (1988). The effects of physiological arousal on information processing and persuasion. J. Consum. Res. 15 , 379-385.

Shemesh, E., Yehuda, R., Milo, O., Dinur, I., Rudnick, A., Vered, Z., and Cotter, G. (2004). Posttraumatic stress, nonadherence, and adverse outcome in survivors of a myocardial infarction. Psychosom. Med. 66, 521-526.

Stone, J., and Cooper, J. A. (2001). Selfstandards model of cognitive dissonance. J. Exp. Soc. Psychol. 37, 228-243.

von Känel, R., Hari, R., Schmid, J. P. Wiedemar, L., Guler, E., Barth, J., Saner, H., Schnyder, U., and Begré, S. (2011). Non-fatal cardiovascular outcome in patients with posttraumatic stress symptoms caused by myocardial infarction. J. Cardiol. 58, 61-68.

Conflict of Interest Statement: The authors declare that the research was conducted in the absence of any commercial or financial relationships that could be construed as a potential conflict of interest.

Received: 03 April 2012; accepted: 23 April 2012; published online: 14 May 2012.

Citation: Edmondson D, Shaffer JA, Denton E-G, Shimbo D and Clemow $L$ (2012) Posttraumatic stress and myocardial infarction risk perceptions in hospitalized acute coronary syndrome patients. Front. Psychology 3:144. doi: 10.3389/fpsyg.2012.00144

This article was submitted to Frontiers in Psychology for Clinical Settings, a specialty of Frontiers in Psychology. Copyright (C) 2012 Edmondson, Shaffer, Denton, Shimbo and Clemow. This is an open-access article distributed under the terms of the Creative Commons Attribution Non Commercial License, which permits non-commercial use, distribution, and reproduction in other forums, provided the original authors and source are credited. 